\title{
Urban sprawl assessment and modeling using landsat images and GIS
}

\author{
Sassan Mohammady ${ }^{1} \cdot$ Mahmoud Reza Delavar $^{2}$
}

Received: 28 July 2016/Accepted: 29 July 2016/Published online: 16 August 2016

(C) Springer International Publishing Switzerland 2016

\begin{abstract}
Nowadays, urban sprawl phenomenon have been seen in many of cities in the developing and developed countries. Urban sprawl is considered as a particular kind of urban growth which comes up with a lot of negative effects. Thus, monitoring, analyzing and modeling of this phenomenon seem to be unavoidable. This paper assess urban sprawl in Tehran Metropolis as the capital of Iran and models urban sprawl in this mega city utilizing artificial neural networks and adaptive neuro-based fuzzy inference system methods with remote sensing data and geospatial information systems spatial analyses and modeling capabilities to simulate Tehran urban growth. The results confirm that this city has experienced sprawl and sprawl has an increasing rate. Three Landsat imageries from TM and ETM+ sensors taken in 1988, 1999 and 2010 and seven predictor variables include distance to road, distance to green space, slope, elevation, distance to fault, distance to developed area and number of urban cells in 3 by 3 neighborhoods have been used for urban sprawl assessment and modeling. Relative operating characteristics (ROC) and sensitivity analyses have been used to evaluate simulation results. In this research, two evaluation steps have been implemented using ROC and on the both of them, ANFIS presented the best performance vs two different proposed ANN structures.
\end{abstract}

Sassan Mohammady

Sassanmohammady@yahoo.com

1 GIS Division, School of Surveying and Geospatial Engineering, College of Engineering, University of Tehran, Tehran, Iran

2 Center of Excellence in Geomatic Engineering in Disaster Management, School of Surveying and Geospatial Engineering, College of Engineering, University of Tehran, Tehran, Iran
Keywords Urban sprawl · Modeling · Tehran Metropolis

\section{Introduction}

In the last century urbanization has increased significantly as a worldwide phenomenon. Urban growth has been accelerating in the past few decades with the massive immigration of population to cities. In 2005, over $50 \%$ of global human population lived in the cities (UNEP 2005). Based on current growth rate, it is estimated that over $60 \%$ of global population will be found in urban areas by 2030 (Moeller and Blaschke 2006; Odindi and Mhangara 2012). Urban area is increasing faster than the urban population itself (Tewolde and Cabral 2011). With this rapid growth, cities exert a heavy pressure on lands and resources available (Leao et al. 2004; Rafiee et al. 2009). Urbanization is the most dramatic form of irreversible land transformation of agricultural and prolific lands to urban areas (Luck and Wu 2002), affecting landscapes and people who live in and around cities. Basically, the transformation of the rural areas to cities and towns can be considered as urban growth, but this urbanization comes up with some costs. Degradation of the environment, above all in the loss of farmlands and forest are some of environmental cost of this phenomenon (Deep and Saklani 2014). Ecosystem structure, function, and dynamics have experienced various impacts in transformation of rural landscapes to urban landscapes (Mesev 2003; Weng 2007). Urban expansion has direct negative effect consists in a physical loss of agricultural land as well as of natural or cultural landscapes, while it has indirect effects, too. Landscape fragmentation, surface sealing, increased run-off, soil erosion as well as biodiversity decline are some of the indirect results of urban growth (Ceccarelli et al. 2014). Also, urban 
growth has caused the deterioration of urban environment, including increased air and water pollution, reduction of vegetation cover and rising level of diseases (Hana et al. 2009). If this unavoidable phenomenon is leaved unchecked, then it causes unplanned urbanization. In fact, unplanned urbanization always create problems like pollution, traffic, deforestation, and congestion of places (Deep and Saklani 2014). Due to crowding, housing shortages, insufficient infrastructure, and increasing urban climatological and ecological problems in urban areas, consistent monitoring of urban regions is unavoidable (Miller and Small 2003). Thus, city managers and resource managers need advanced and reliable methods and a comprehensive knowledge of cities to make the informed decisions necessary to guide sustainable development in rapidly changing urban environments (Pham et al. 2011).

Nowadays, urban systems are regarded as complex, selforganizing and non-linear systems, where the dynamic transitions from one form of land use to another occur over a period of time (Sathish Kumar et al. 2013). Spatial models are developed to achieve a balance between the environment and the management of scarce resources (Goudie 2006) which supports the adequate decisionmaking strategies. Using these models, policy makers and urban managers can analyze different scenarios of land cover and land use change and also, evaluate their effects. Thus, such models can be useful and unavoidable in land use policy and planning (Rafiee et al. 2009; Veldkamp and Lambin 2001). In fact, urban expansion modeling is an interdisciplinary field as it involves numerous scientific areas, such as GIS, complexity theory, urban geography and remote sensing (Cheng 2003; Rui 2013). In this situation, GIS and remote sensing are proven as very powerful science and technology for managing and analyzing spatial information and extracting valuable information concerning urbanization and its dynamics (Hasse 2007; Kumar et al. 2008; Masser 2001). In the recent past decade, there has been increasing research attention on the use of remote sensing, GIS and photogrammetric data in the simulation modeling of urban growth (Dadras et al. 2015). Urban expansion models attempt to recognize land transformer factor, their importance and project future changes in urban areas based on historical trends (Pijanowski et al. 2009) and also, to project spatial changes in land use based on scenarios of changes in its drivers (Meiyappan et al. 2014).

During last decades, artificial intelligence (AI) and computational based algorithms have been used in so many researches including engineering and non-engineering area due to their abilities. Artificial neural networks is one of the most popular AI methods which have been used widely in so many topics. Ability of dealing with large volume of data, fast processing, pattern cognition and learning ability, parallel processing and the ability of dealing with noised data, made this algorithm so popular. ANNs have been used in land use change modeling and urban growth modeling by (Pijanowski et al. 2009, 2002, 2014; Tayyebi et al. 2011; Li and Yeh 2001; Almeida et al. 2008). However, this method has some disabilities, too. One of the most important disadvantages is that it is unable to deal with uncertainty. Uncertainty is an unavoidable part of spatial phenomena (Al-Kheder et al. 2008) and needless to say its importance in so many concepts of this science like neighborhood, topology (relations between objects), buffer and other topics which clearly, 0 or 1 does not clarify and present them properly. In this condition, fuzzy logic has the ability to work with uncertainty. Thus, combination of these methods can discard many of their disabilities individually. By integrating artificial neural networks and fuzzy inference systems, the capabilities of ANNs selflearning with the linguistic expression function of fuzzy inference can be fused (Pahlavani and Delavar 2014) and also, overcome many of their shortages. In this research, we propose an ANFIS structure for urban land use change modeling and compare the results of the proposed model with predefined ANNs ones.

\section{Materials and methods}

In this study, Tehran urban sprawl assessed and modeled for 1988, 1999 and 2010. Figure 1 presents the research flowchart. At first, data preprocessing have been done. After classification, urban sprawl assessment has been analyzed using Shannon's Entropy. Then, urban growth modeling using proposed ANFIS structure have been done and then, modeling have been done using ANN structure for comparing with ANFIS result ones for 1999 and 2010. Relative operating characteristics (ROC) has been used for evaluating goodness of fit of these models. Finally, sensitivity analysis has been used for clarification of each factor effect in Tehran urban growth during 1988-2010.

\section{Study area}

Iran as a developing country in Asia, is witnessing continual large-scale urbanization (Rafiee et al. 2009; Hosseinali et al. 2013). Urban population in Iran has increased from $47 \%$ in 1976 to $61 \%$ in 1996 (Rafiee et al. 2009; Fanni 2006) and number of towns and cities in Iran has also increased significantly, from 199 towns in 1956 to 1200 in 2012 (Statistical Center of Iran). The case study in this research is Tehran Metropolis. Tehran's residential population, nearly doubled from 1975 to 2010 and this fast population growth made the city the world's 17th-largest and one of the cities with the largest annual growth in Asia (Jokar Arsanjani et al. 2013; World Gazetteer 2012). 
Data collection \& preparation

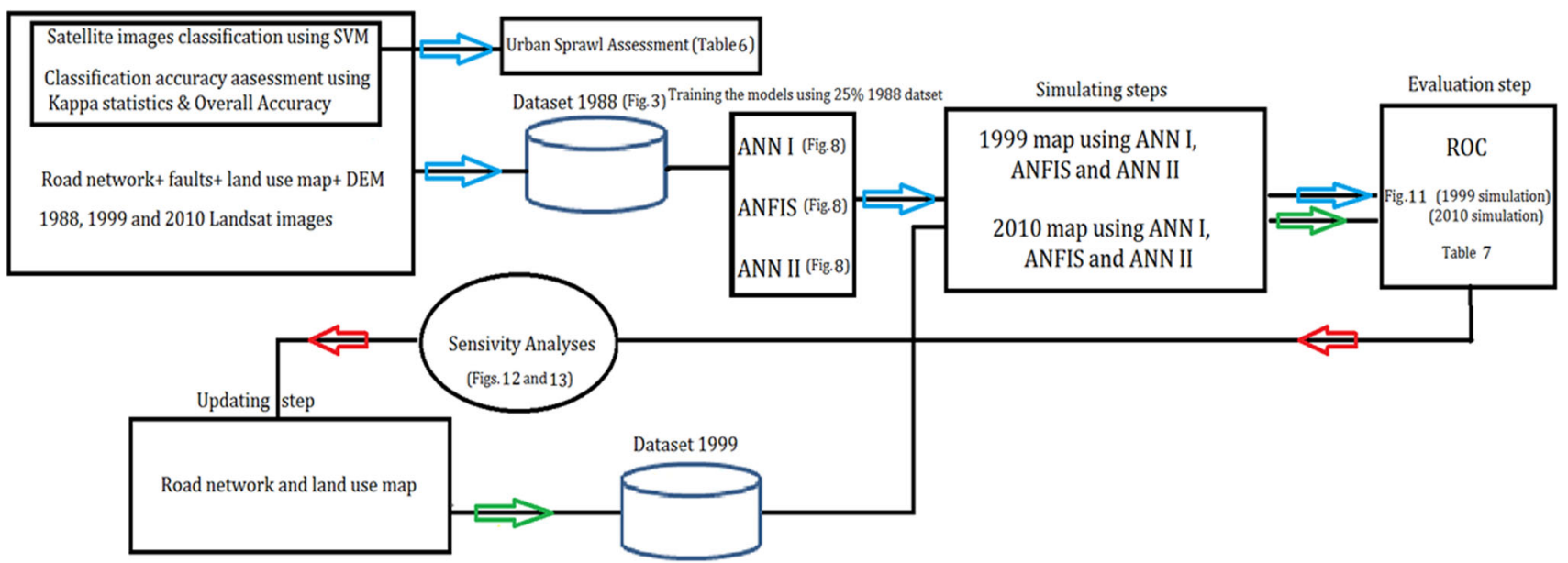

Fig. 1 Research flowchart

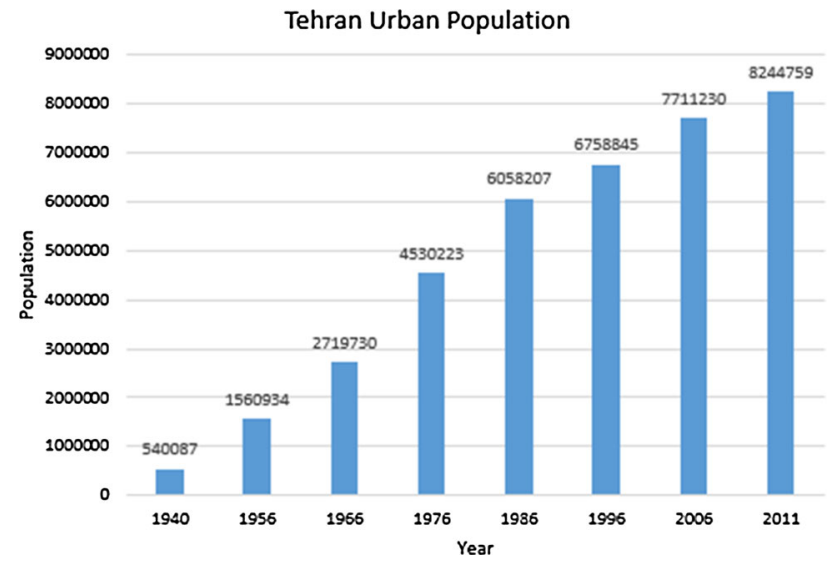

Fig. 2 Tehran remarkable growth in the past few decades

Tehran has shown remarkable growth in the past few decades (Fig. 2). Migration from nearby cities and even provinces to the city because of its economic and social attractiveness are the most important reasons for the rapid population growth.

\section{Data preparation}

Satellite imageries has played an important role in the assessment of urbanization by measuring land use and land cover change for cities and their surroundings (Alberti et al. 2002; Jürgens 2003). Remote sensing as a reliable source of data, provides spatially consistent coverage of large areas with temporal frequency and high spatial detail, which are useful for analyzing time dependent phenomenon such as urban expansion (Jensen and Cowen 1999). As a result, remote sensing is an effective and accurate source of data for monitoring urban expansion, especially where information on land use management is inconsistent and insufficient. In this study, three Landsat imageries from TM and $\mathrm{ETM}^{+}$sensors which came from 164 and 35 for row and column, respectively, acquired in 1988, 1999 and 2010 were rectified and registered to Universal Transverse Mercator (UTM) WGS 1984 zone 39N. Support vector machine (SVM) classification was used to classify the imageries to different land-use categories according to Anderson level 1 (Anderson et al. 1976) using ENVI 4.8. SVM gives better results than the traditional classifiers like maximum likelihood (Melgani and Bruzzone 2004; Huang et al. 2002; Pal and Mathur 2005). Support vector machines (SVMs) are superior image classification techniques in airborne and satellite imagery, applying a set of machine learning algorithms and having their roots in statistical learning theory (Erfanifard et al. 2014). Due to its ability to handle the nonlinear classifier problem, SVM is able to go beyond the limitations of linear learning machines by implementation of the kernel function, which paves the way to find a nonlinear decision function (Aghababaee et al. 2013). User accuracies and producer accuracies of all of classifications are presented in Tables 1,2 and 3. Overall accuracy and Kappa of classification assessment of these imageries are presented in Table 4. According to (Pijanowski et al. 2005), Kappa obtained from all of the three imageries, classified as excellent and according to (Thomlinson et al. 1999; Anderson et al. 1976), all of the obtained overall accuracies are acceptable. The database developed for this study includes distance to road, distance to developed area, distance to green space, and elevation, slope, number of urban cell in a $3 * 3$ neighborhood and distance to fault (Fig. 3). The elevation data came from AsterDEM 1996. Also, slope data obtained directly from the AsterDEM 1996 using ENVI 4.8. The layers of roads, developed areas, green 
Table 1 User and producer accuracy (1988)

\begin{tabular}{lllll}
\hline CLASS & User accuracy (\%) & Producer accuracy (\%) & User accuracy (Pixel) & Producer accuracy (Pixel) \\
\hline Building & 87 & 93.8 & $3058 / 3515$ & $3058 / 3260$ \\
Road & 69.03 & 39.61 & $263 / 381$ & $263 / 664$ \\
Vegetation & 98.83 & 99.8 & $1014 / 1026$ & $1014 / 1016$ \\
Bare ground & 96.34 & 96.64 & $5587 / 5799$ & $5587 / 5781$ \\
\hline
\end{tabular}

Table 2 User and producer accuracy (1999)

\begin{tabular}{lllll}
\hline CLASS & User accuracy $(\%)$ & Producer accuracy $(\%)$ & User accuracy (Pixel) & Producer accuracy (Pixel) \\
\hline Building & 93.78 & 96.6 & $3149 / 3358$ & $3149 / 3260$ \\
Road & 83.53 & 65.53 & $289 / 346$ & $289 / 441$ \\
Vegetation & 98.13 & 98.01 & $787 / 802$ & $787 / 803$ \\
Bare ground & 98.07 & 98.04 & $5190 / 5292$ & $5190 / 5294$ \\
\hline
\end{tabular}

Table 3 User and producer accuracy (2010)

\begin{tabular}{lllll}
\hline CLASS & User accuracy $(\%)$ & Producer accuracy (\%) & User accuracy (Pixel) & Producer accuracy (Pixel) \\
\hline Building & 95.53 & 97.73 & $3186 / 3335$ & $3186 / 3260$ \\
Road & 90.8 & 82.77 & $1365 / 402$ & $365 / 441$ \\
Vegetation & 99.04 & 99.13 & $1139 / 1150$ & $1139 / 1149$ \\
Bare ground & 97.97 & 97.19 & $4526 / 4620$ & $4526 / 4657$ \\
\hline
\end{tabular}

Table 4 Classification accuracy assessment

\begin{tabular}{lll}
\hline Image & Overall accuracy $(\%)$ & Kappa statistics \\
\hline 1988 & 92.55 & 0.875 \\
1999 & 96.09 & 0.933 \\
2010 & 96.94 & 0.951 \\
\hline
\end{tabular}

spaces and the number of urban in a $3 * 3$ neighborhoods obtained from classified imageries data. The layer of fault, has been used in ArcGIS 9.3. All of the input data normalized between 0 and 1 . Normalization of the input data to a uniform range before applying them, prevent larger numbers from prevailing smaller ones and also, to scale data in the same range of values for each input feature in order to minimize bias within the dataset for one feature to another (Wu et al. 2005).

\section{Urban sprawl assessment}

After land use classification, the urban areas have been extracted from Landsat imageries and are shown in Fig. 4. The urban and non-urban area in this city for 1988, 1999 and 2010 are presented in Fig. 5. According to Bhatta (2009), an even policy for the entire city (all parts) never works with equal degree of effectiveness for all parts of the city and study area should divides to smaller region to study the sprawl in them. Thus, the map is divided into 4 regions (SW, SE, NW and NE regions). Figure 6 presents urban area in NW, NE, SW and SE directions during 1988-2010.

\section{Shannon's entropy}

In this study, Shannon entropy has been implemented for analyzing urban sprawl during 1988-2010 in Tehran Metropolis. Shannon's entropy as a well-accepted manner in assessment of urban sprawl has been used in a variety of researches like (Sudhira et al. 2004; Bhatta 2009; Li and Yeh 2004). In fact, Shannon entropy, as a scientific method determine the city is sprawled or not. The Shannon's entropy is considered a follows:

$H_{i}=-\sum_{j=1}^{m} p_{j} \log _{e}\left(p_{j}\right)$

$\mathrm{i}=$ temporal span $\mathrm{j}=$ target zone $p_{j}=$ proportion of the variable in the $\mathrm{j}$-th target by: built-up growth in $\mathrm{j}$-th zone/sum of built-up growth rates for all zones and $\mathrm{m}=$ number of zones.

The Shannon entropy values ranges from 0 to loge(n), values closer to 0 (smaller values) indicates very compact distribution and the value closer to loge(n) (larger values) 

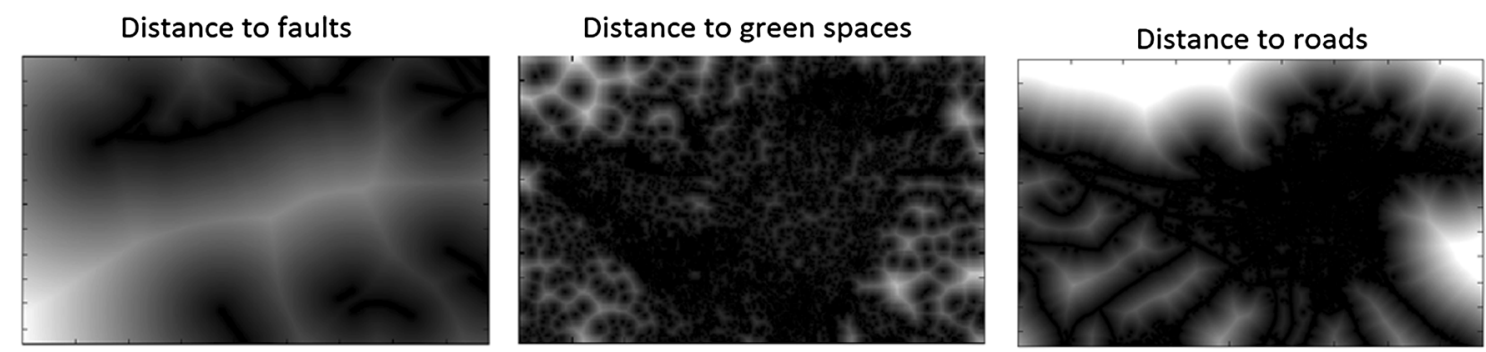

Number of urban cell in a 3*3 neighborhood
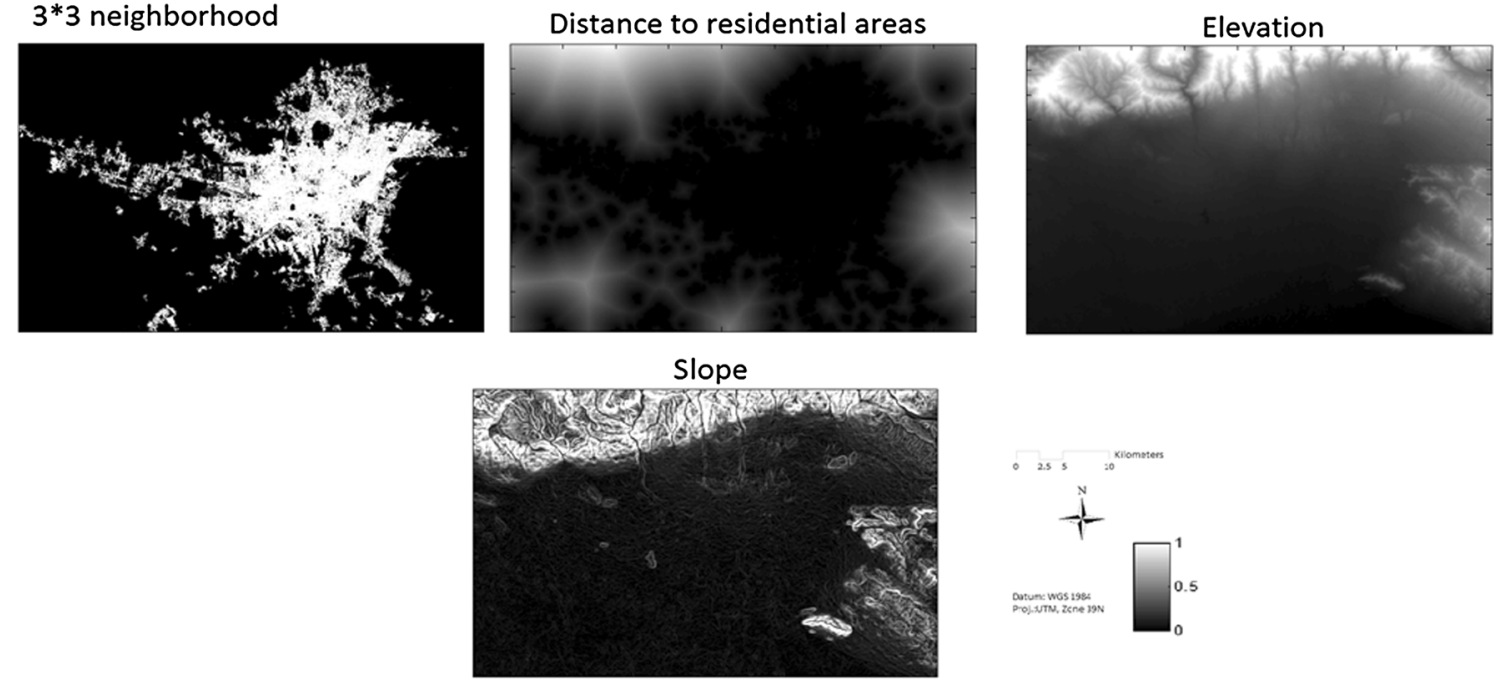

Fig. 3 Implemented input data
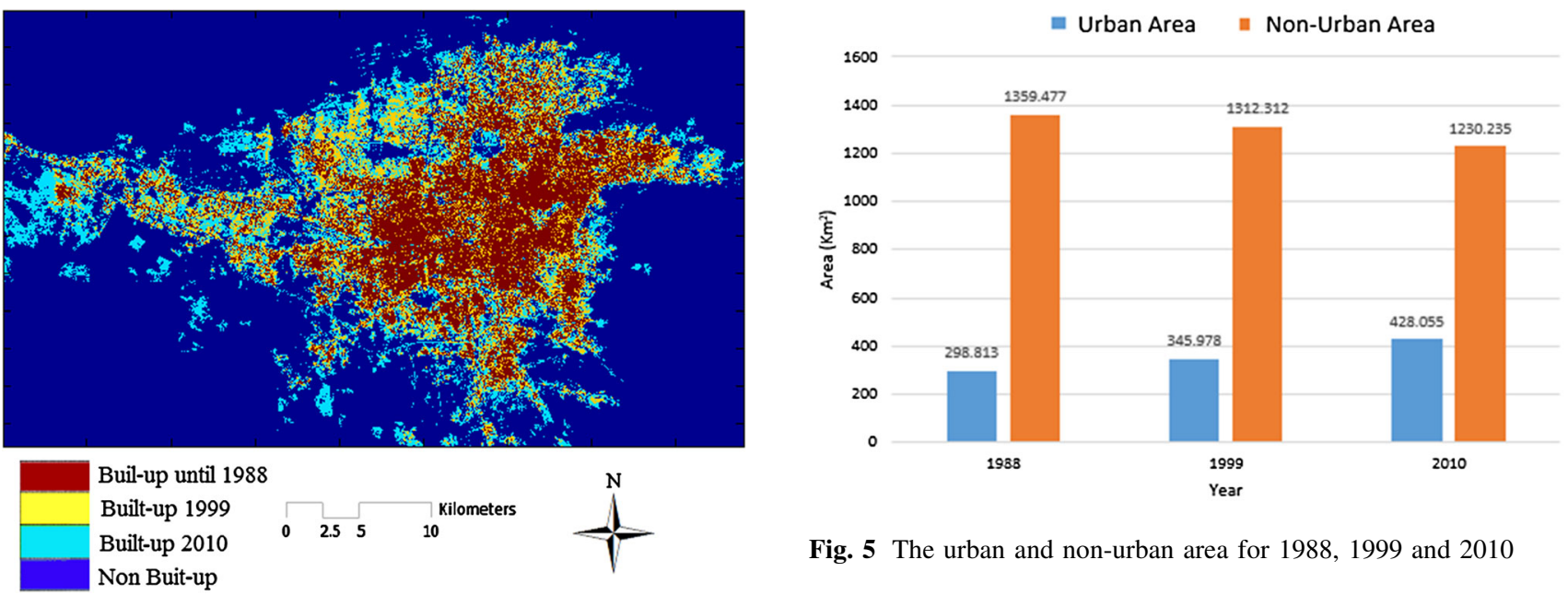

Fig. 5 The urban and non-urban area for 1988, 1999 and 2010

Fig. 4 Urban areas have been extracted from Landsat imageries

indicates that the distribution is much dispersed (Bhatta 2009).

In this research, $\mathrm{i}=$ temporal span (here is 1988-1999 and 1999-2010. i.e. 1, 2), $\mathrm{j}=$ target zone (SW, SE, NW and $\mathrm{NE}$ ), $p_{j}=$ proportion of the variable in the $\mathrm{j}$-th target (calculated (Table 5) by: built-up growth in j-th zone/sum

of built-up growth rates for all zones and $\mathrm{m}=$ number of zones $=4$. The urban sprawl assessment is presented in Table 5.

The results of urban sprawl assessment confirm that this city has experienced sprawl. The results show that Tehran is becoming more sprawled. In fact, the Shannon's entropy values is becoming bigger during two period (1988-1999 and 1999-2010). This Megacity due to population growth, attraction of the city as the capital of Iran and social, 


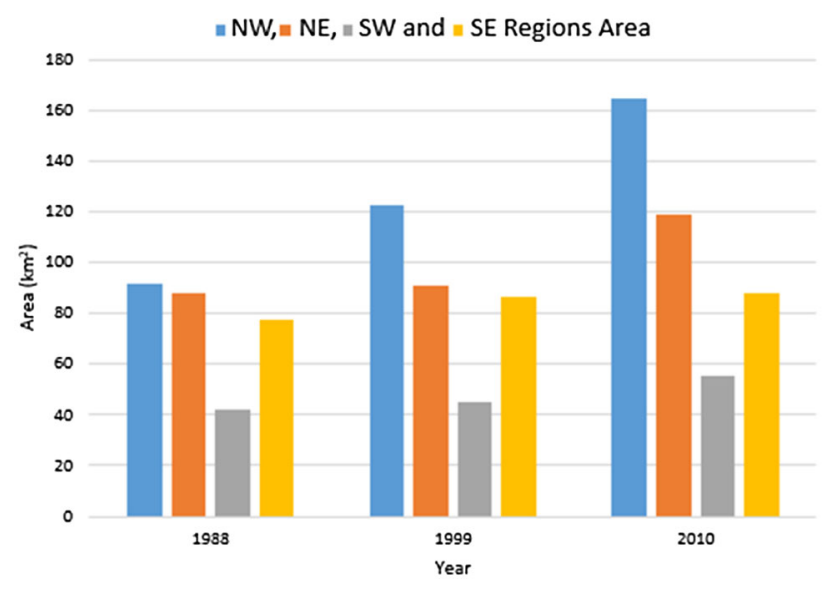

Fig. 6 Urban area in NW, NE, SW and SE directions during 1988-2010

Table 5 Sprawl assessment

\begin{tabular}{ll}
\hline Temporal span & Shannon entropy \\
\hline $1988-1999$ & 0.9667 \\
$1999-2010$ & 1.0422 \\
\hline
\end{tabular}

economic potential of the city have increased very fast. These factors have resulted urban land and urban population growth very fast in this city (Mohammady and Delavar 2015).

\section{Urban sprawl modeling}

In the last two decades, due to accessibility to free to less expensive remote sensing data, GIS tools and using spatial analyzing tools and high computing capability computers, modeling of urban growth has significantly accelerated. These models usually classify to raster based and vector based method (Hu and Lo 2007). Raster based method are so popular due to simplicity of the definition of their environment. ANN is one of the most common raster based methods in urban growth modeling (Triantakonstantis and Mountrakis 2012) due to parallel processing and pattern recognition ability which has been used by (Pijanowski et al. 2002; Li and Yeh 2001; Almeida et al. 2008; Tayyebi et al. 2011). This method has some disadvantages such as lack of flexibility. It is also, unable to deal with qualitative uncertainty. Another popular raster based method is Logistic Regression (Triantakonstantis and Mountrakis 2012) due to simple structure which has been used in urban growth modeling by (Hu and Lo 2007; Tayyebi et al. 2010; Xie et al. 2009; Huang et al. 2009; Dubovyk et al. 2011). This method is also, unable to recognize non-linear relations. And finally, cellular automata is the most popular method in urban growth modeling (Triantakonstantis and Mountrakis 2012) which has been used by (Batty et al. 1999; Liu 2009; Maithani 2010; Foroutan and Delavar 2012). Finding the proper transferring rule is the most important disadvantage of cellular automata method. As mentioned, there are some disadvantages in these models. Thus, implementation a structure which modify all or part of the mentioned disadvantages help the pattern and relation between effective factors recognized better and consequently the training procedure and modeling process done completely. In this study, we proposed an ANFIS structure for modeling urban growth and compare the ANFIS results with ANN result which is one of the most common methods in urban growth modeling.

\section{ANFIS}

Fuzzy inference system ability to apply human knowledge and expertise which makes it very close to human perception is one of the most important features of it. Also, it is considered as a powerful tool for modeling uncertainties associated with human cognition, thinking and perception (Gupta and Rao 1994). Fuzzy inference allows us to linguistically describe the concepts related to urban growth (Al-Kheder et al. 2008) which flexibility is one of its advantages. The most important problem in fuzzy inference systems is finding proper membership function for each fuzzy variable which can be solved by training only. ANN as the one of the most common methods in urban growth modeling has the ability to learn pattern and relationship between data from training data. By combining ANN and fuzzy inference systems, learning and human knowledge can be integrated together and at the same time, it covers many of their shortcomings (Pahlavani and Delavar 2014), such as the problem of finding the correct position and shapes for membership functions in fuzzy inference system and lack of flexibility in neural network. In other words, ANFIS take advantage of learning, use of human knowledge and flexibility which makes it very suitable to solve some of the problems. In this algorithm, during the training process, membership functions change (in figures and location) toward their optimal values. ANFIS was first proposed by Jang (1993) based on the Takagi-Sugeno model based fuzzy inference systems and neural network structures (Jang 1993). ANFIS is a multi-layer adaptive network-based fuzzy inference system which has been widely employed in many fields. A typical two input ANFIS architecture is shown below (Fig. 7).

Layer 1 For any node, the output is:

$O_{1, i}=\mu_{A_{i}}(x) \quad$ for $i=1,2$, 
Fig. 7 A typical two input ANFIS architecture

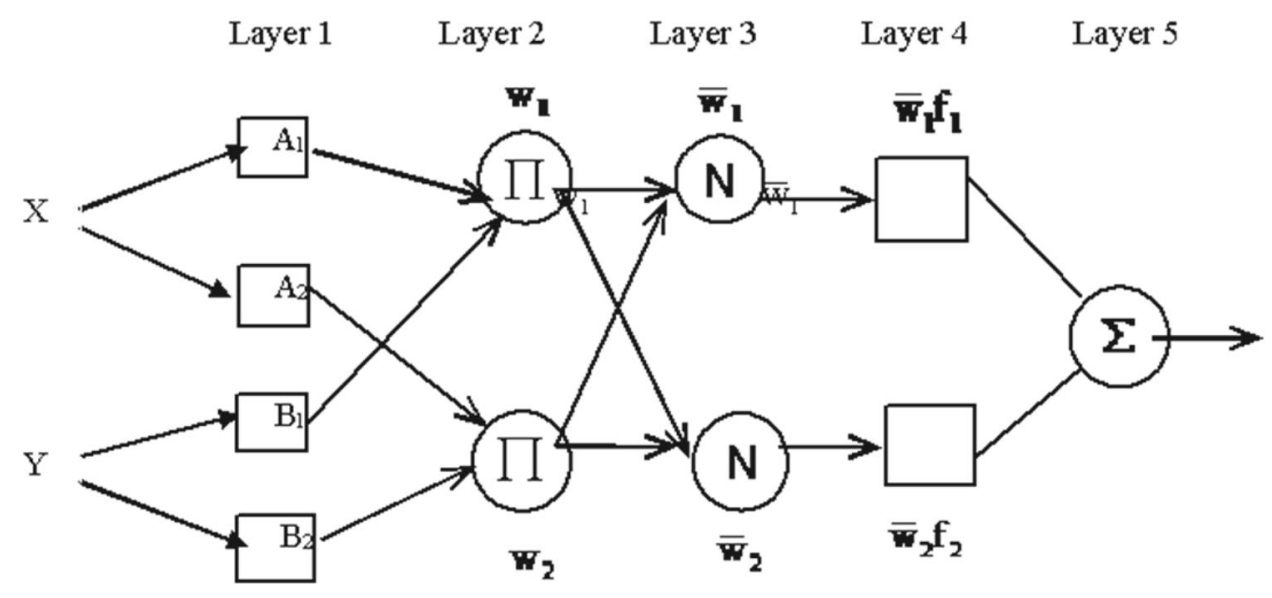

$O_{1, i}=\mu_{B_{i-2}}(y) \quad$ for $i=3,4$,

Every node in this layer is an adaptive node. There is no limitation about the membership functions but in this study we have used Gaussian membership function as follows:

$\mu_{A_{i}}\left(x ; \sigma_{i}, c_{i}\right)=\exp \left(-\left(x-c_{i}\right)^{2} / 2 \sigma_{i}^{2}\right)$,

where $\sigma_{i}$ and $c_{i}$ are parameters to be learnt.

Layer 2 Every node in this layer is a fixed node. This is where the t-norm is used to 'AND' the membership grades-for example the product:

$O_{2, i}=w_{i}=\mu_{A_{i}}(x) \mu_{B_{i}}(y), \quad i=1,2$.

Layer 3 This layer, contains nodes which calculates the ratio of the firing strengths of the rules:

$O_{3, i}=\bar{w}_{i}=\frac{w_{i}}{w_{1}+w_{2}}$

Every node in this layer is a fixed node. The ith node of this layer normalizes the firing strength of the previous node with respect to firing strengths of others.

Layer 4 The layer 4's nodes are adaptive and perform the consequent of the rules. The output of this node is given by:

$O_{4, i}=\overline{w_{i}} f_{i}=\overline{w_{i}}\left(p_{i} x+q_{i} y+r_{i}\right)$,

The parameters in this layer $\left(p_{i}, q_{i}, r_{i}\right)$ are to be determined and are referred to as the consequent parameters.

Layer 5 There is a single node here (a fixed node) that computes the overall output and acts as an accumulator and it adds up all the outputs coming from the previous layer to give the final classifier function as,

$O_{5, i}=\sum_{i} \overline{w_{i}} f_{i}=\frac{\sum_{i} w_{i} f_{i}}{\sum_{i} w_{i}}$,

\section{ANN}

The time-space relationship as an unavoidable parts of urban dynamic process, plays an important role in understanding the dynamic urban growth process. This process consists of a nonlinear and complex interaction between several components. Such nonlinear relationships between land use change and its driving factors can be addressed smoothly by artificial neural network (ANN) modeling framework as evidenced by Yeh and Li (2003), Almeida et al. (2008). Artificial neural network due to the possibility of learning is an appropriate tool for environmental modeling. One of the key issues in this research was the design of the neural networks architecture. A number of mathematical formulations have proposed to determine hidden neurons by different researchers, but until now they have not yet come to an agreement on a certain method to determine the optimal number of the hidden layers and the ideal number of neurons in the hidden layer (Almeida et al. 2008). According to Kavzoglu and Mather (1999), Paola and Schowengerdt (1997), nets with more neurons being less influenced by the initial random weights and capable to learn more complex patterns. Also, according to (Haykin 1999), nets with more neurons demand more time for training and do not generalize well with unknown data. However, there is a general consensus among researchers in the field of urban modeling that empiricism is a reasonable way to determine the most optimum and the best structure in neural net for a specific problem (Yeh and $\mathrm{Li}$ 2003; Li and Yeh 2001; Guan and Wang 2005; Almeida et al. 2008). In this study, we implemented ANN algorithm in two different structures. For the first one, according to (Pijanowski et al. 2002), the input data has been normalized between 0 and 1 . Sigmoid function has been used in the hidden layer and output layer as the transfer function 
(Pijanowski et al. 2009; Tsoukalas and Uhrig 1997). A structure including seven input neurons, 15 neurons for hidden layer and one neuron for output layer have been used. For the second one, the input data has been normalized between -1 and 1 . This kind of normalization helps our data to have negative values, too. This enables negative values to play their role in calculations, equations and nets weights values. The second proposed structure including seven nodes in input layer, 15 nodes in the hidden layer and 2 nodes (urban and non-urban) in the output layer. Tang-sigmoid in the hidden layer and linear function in the output layer as the transfer function are used. Tangsigmoid has been used to model the non-linear space and linear function has been used to model the linear spaces of the structure.

\section{Selection of training data and calibration}

The overall number of cells in this study come from a satellite image with 1760 cells by 1160 cells dimension $(2,041,600$ cells). The training points (training data) in this study area included $10 \%$ of all the cells (in fact 200,000 cells). $25 \%$ of the training cells $(50,000$ cells $)$ are entered the models (ANFIS and ANNs) to train them and estimate the bias and parameters and $75 \%$ of training data (rest of training data equal to 150,000 cells) are used as the data check. The training data have been chosen randomly in an unbiased manner in a way that are chosen from all the image space. These 200,000 cells were approximately $10 \%$ of the 1988 image data which have been used for calibrating the models which means training and checking for ANN and ANFIS models. The rest of data 1988 data (90\% of all) were used for first step goodness of fit assessment [comparing simulated data (1999 map) with real one] using ROC. In the second accuracy assessment step, the 2010 map simulated using the three models and compared with real 2010 map (Ground truth) and ROC has been used for evaluating goodness of fit of these simulated maps with reals ones.

\section{Accuracy assessment factor}

In this research, relative operating characteristics (ROC) proposed by (Pontius and Schneider 2001), as an excellent method to evaluate the goodness of fit between the simulated and real maps ( $\mathrm{Hu}$ and $\mathrm{Lo} 2007)$, has been used to evaluate the goodness of fit. ROC is a threshold independent method (Beguería 2006) which ranges between 0 and 1. A ROC value 1 means there is complete agreement between simulated and real maps while 0.5 means random distribution of land uses. ROC curve plots the rate of true positive (Eq. 9) to positive classifications against the rate of false positive (Eq. 10) to negative classifications as
Table 6 Confusion matrix

\begin{tabular}{llll}
\hline Model & Reality & & \\
\cline { 2 - 4 } & Change & Non-change & Total \\
\hline Change & $A$ & $B$ & $A+B$ \\
Non-change & $C$ & $D$ & $C+D$ \\
Total & $A+C$ & $B+D$ & $A+B+C+D$ \\
\hline
\end{tabular}

threshold value change from 0 to 1 (Foroutan and Delavar 2012). The true positive and false negative obtain from confusion matrix (Table 6) (Hu and Lo 2007). A set of true positive and false positive can be calculated with applying each threshold value between 0 and 1 .

True Positive $\%=\frac{A}{A+C}$,

False Positive $\%=\frac{B}{B+D}$,

\section{Results}

The training procedure of models are continued until the threshold value is achieved. Number of the epochs or predefined root mean squared error (RMSE) value can be considered as the threshold value. In this research, the number of epochs has been chosen as the threshold value. ANN (I) error curves are shown in Fig. 8. The ANN (I) error curve (RMSE) for training and checking data starts around 0.65 and reached under 0.3 after 500 epochs for both of them. The ANN (II) error curve for training and checking data (Fig. 8) starts around 1.1 and after 1000 epochs reached around 0.8 for the checking data and under 0.6 for the training data. The ANFIS error curves for the training and checking data (Fig. 8) starts around 0.291 and after 500 epochs reached under 0.284. Using the ANFIS model described about, we have used Gaussian membership function with 0.1 as the initial step size. The step size decreasing rate and step size increasing rate were selected equal to 0.9 and 1.1 , respectively. In this study, due to large volume of the training data (large dimension), the sub clustering method implemented for generating FIS structure. Sub clustering method is a well-known method in generating FIS structure for the big size data. Sub clustering method selects the number of membership function from the input data. The input membership functions and final membership functions are showed in Fig. 9. ANFIS method had the least RMSE value according to Fig. 8. On the other hand, ANN (II) had the highest RMSE (Fig. 8).

After the models calibrated using historical data 1988 (10\% of all), the models simulated the 1999 map and then, future (year 2010) urban expansion based on urban 

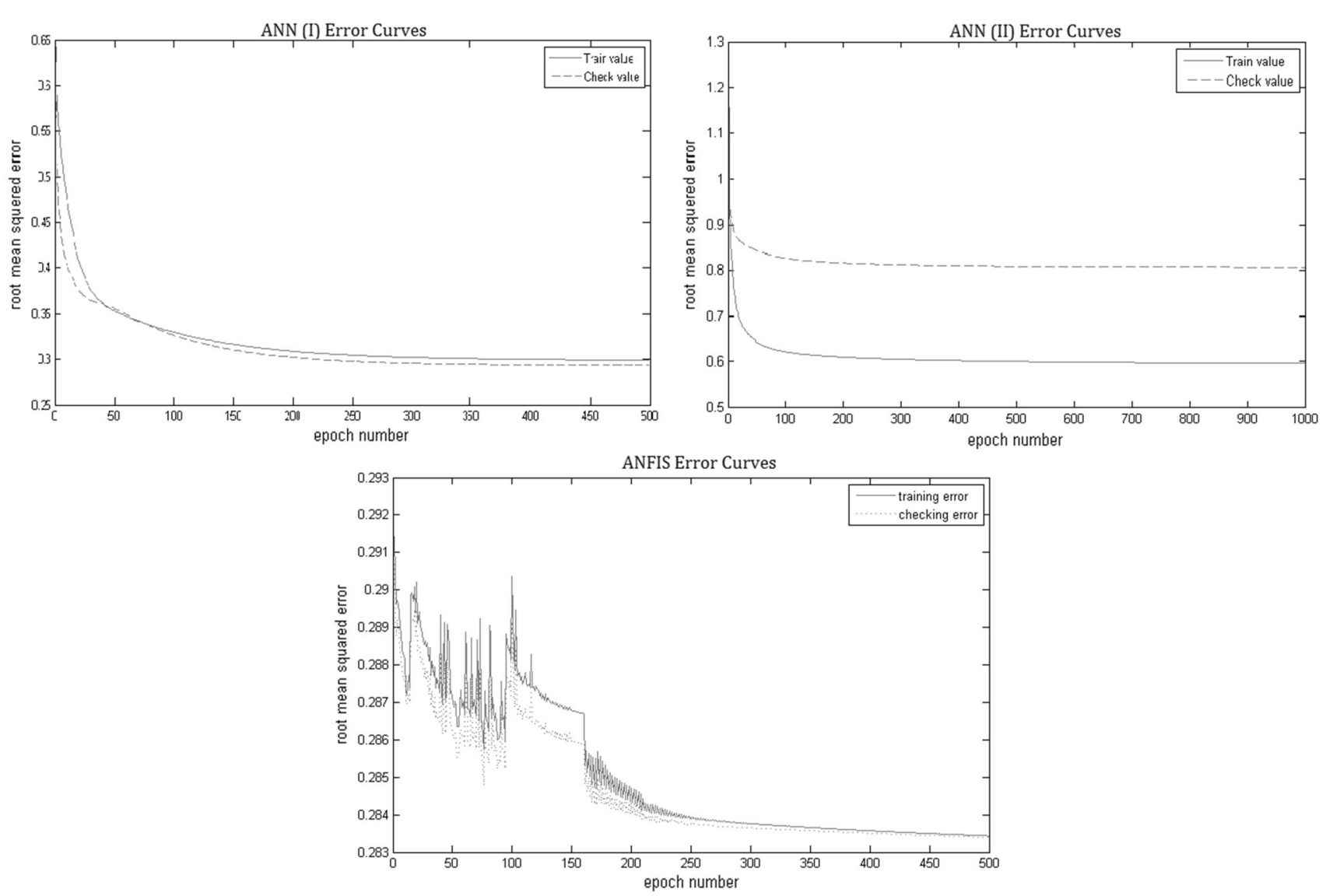

Fig. 8 The models error curve
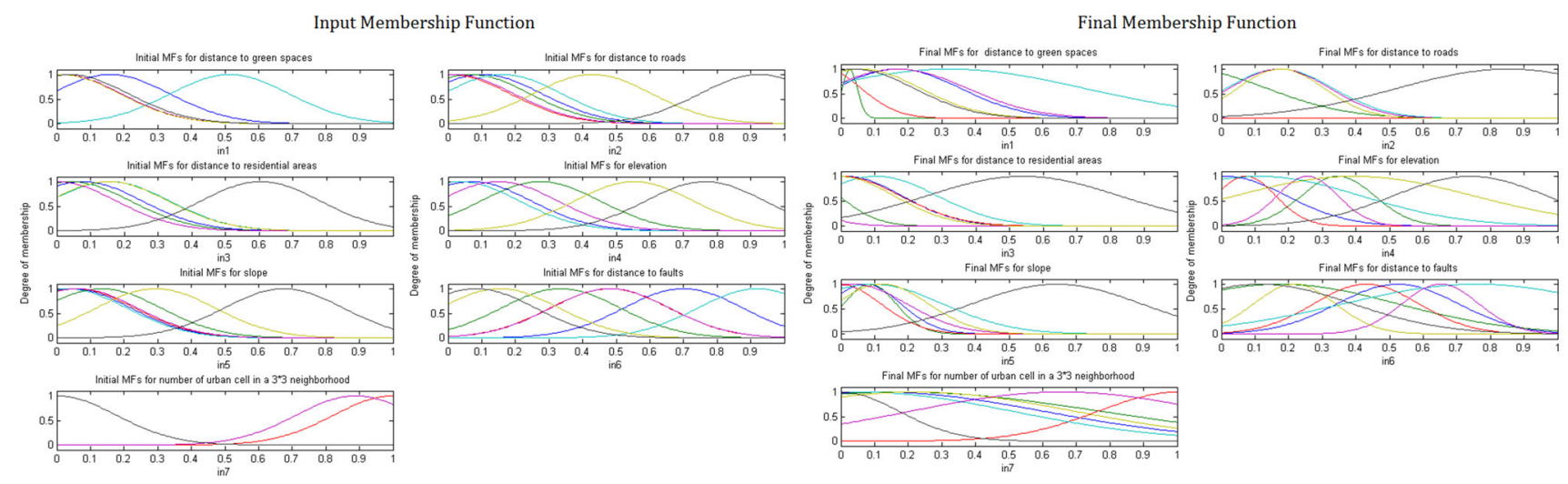

Fig. 9 Input membership functions and final membership functions

expansion trends (1988-1999). The accuracy obtained from the modeling using the three models are shown in Table 7 and Fig. 10. According to the results shown in Table 7 and Fig. 10, ANFIS approach had the best ROC value and goodness of fit among the three models (ANFIS, ANN (I) and ANN (II)) in modeling urban expansion for Tehran Metropolis in 1988-1999 and 1999-2010, too.
As it mentioned in the Table 7, the proposed ANFIS structure had the best goodness of fit in two accuracy assessment steps (1988-1999 and 1999-2010). Thus, this method is chosen as the modeler of Tehran urban growth and consequently, the 1999 and 2010 Tehran's map simulated by ANFIS model. Figure 11 present the simulated 1999 and 2010 map. 
Table 7 The simulation results

\begin{tabular}{lll}
\hline Method & $\begin{array}{l}\text { ROC obtained from } \\
\text { simulation 1999 map }\end{array}$ & $\begin{array}{l}\text { ROC obtained from } \\
\text { simulation 2010 map }\end{array}$ \\
\hline ANFIS & 0.9205 & 0.8642 \\
ANN (I) & 0.9022 & 0.6193 \\
ANN (II) & 0.9025 & 0.7148 \\
\hline
\end{tabular}

\section{Sensitivity analyses}

For obtaining sensitivity analyses, each of the input data have removed and then, ANFIS, ANN (I) and ANN (II) trained, separately and simulated 1999 maps and calculated ROC. Sensitivity Analyses is used to clarify the importance of each input variable in modeling of Tehran Metropolis expansion. Figure 12 shows the SA results according to the
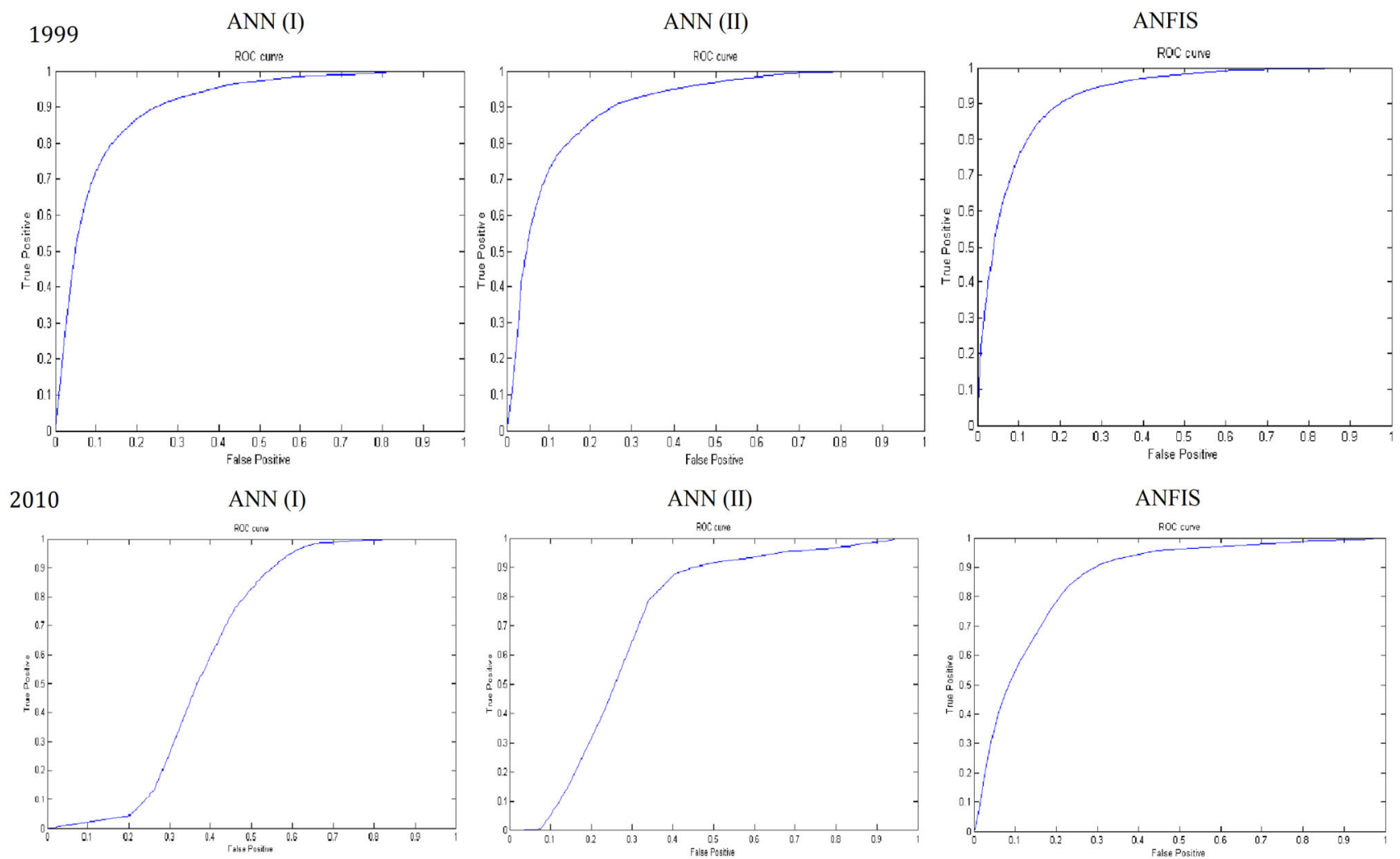

Fig. 10 Accuracy obtained from the modeling using the three models
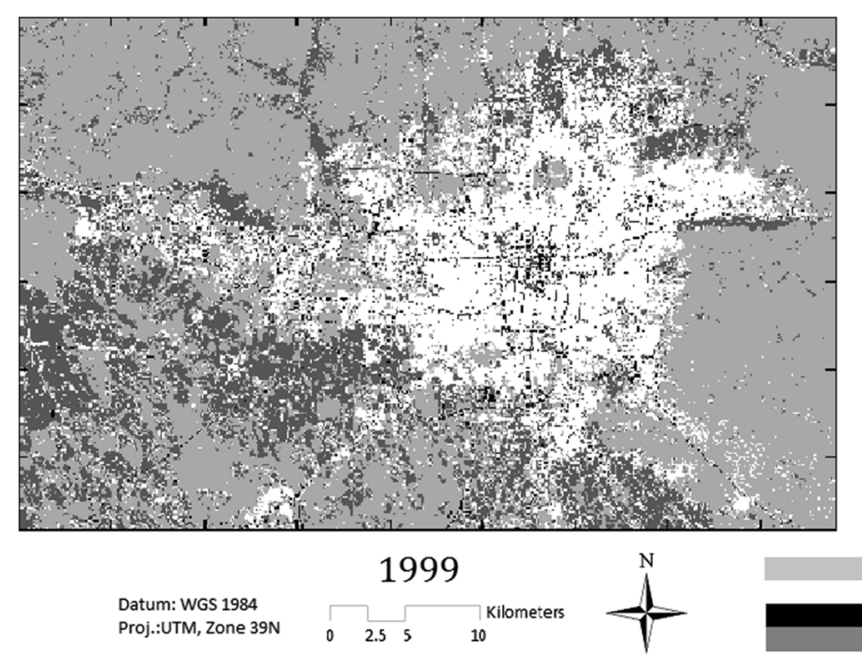

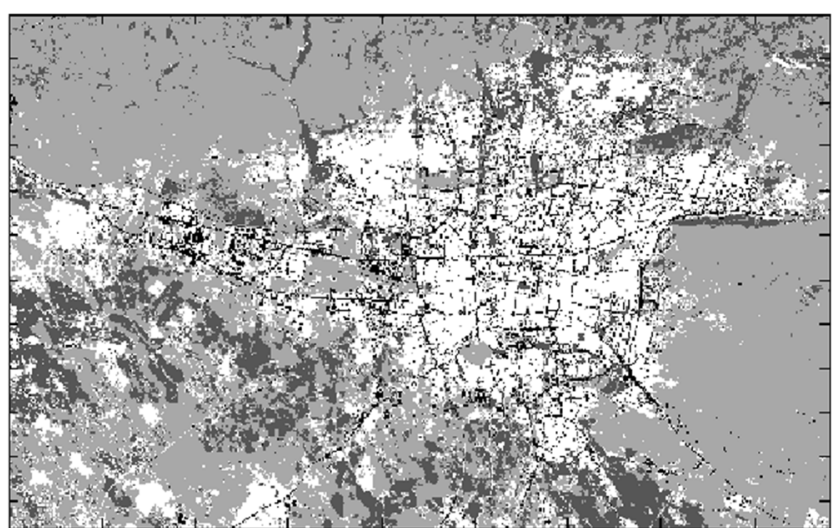

Barren

Urban

Street
Vegetation
2010

Fig. 11 The simulated 1999 and 2010 map 


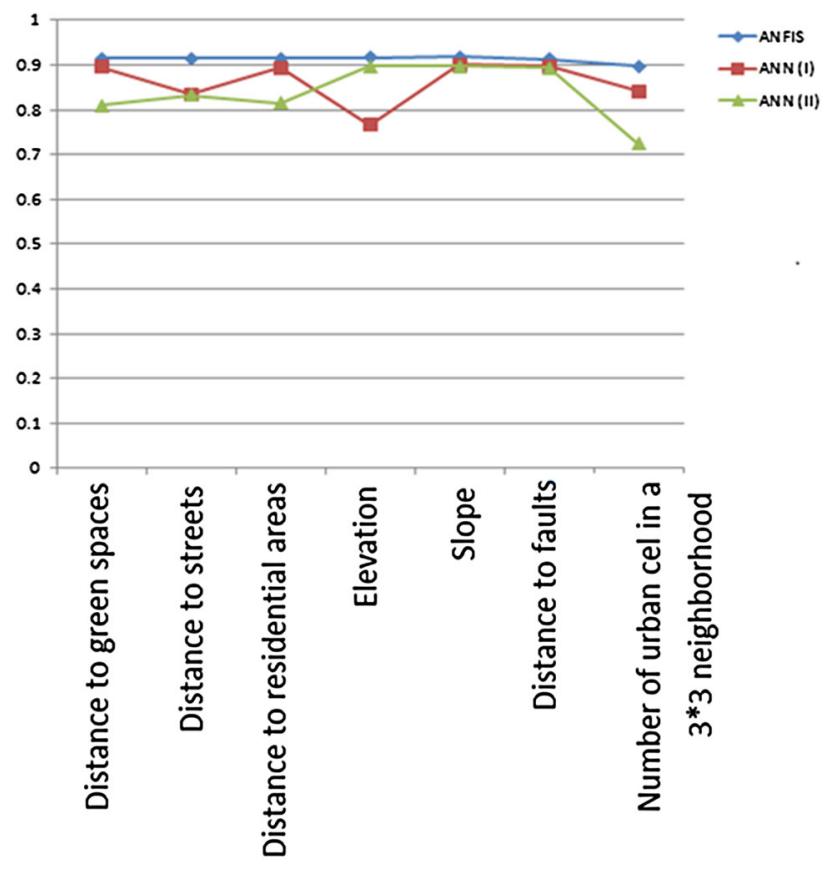

Fig. 12 Sensitivity analyses results

1988-1999 data. Figure 13 shows the ROC obtained from deleting each variable from calculation to determine the importance of the variable.

\section{Discussion}

In Figs. 12 and 13, it seems that slope due to high value of ROC, in all the three models had the least impact on expansion of the Tehran Metropolis during 1988-2010. Because the ROC resulted by deleting this factor, has had the least difference from modeling using all of the implemented factors. On the other hand, the number of urban cell in a 3*3 neighborhood, had the least ROC values in ANFIS and ANN (II) method and was the third important factor in ANN (I) modeling. It seems that this factor has had a noticeable impact on the expansion of Tehran during 1988-2010. Thus, probably, this factor has had the highest impact on growth of Tehran, and rapid growth of north region of this city is confirmable. During 1988-2010, the areas built up in the north have experienced more and rapid growth than others.

As observed from the existing growth trends until 2010, risk assessments factor such as distance to faults have had a small role in the development of this city. Needless to say that this factor could be a big challenge at high dense and informal urban areas.

ANFIS as a combined method solves many of the weaknesses of ANN and fuzzy inferences systems approaches and uses the advantages of these methods, at the same time. On the other hand, it has some drawbacks like ANFIS never has been as fast as ANN models. Also, ANFIS run-time correlates with the number of membership function in each input.

According to Table 7 ANN (I) had the lowest ROC result and goodness of fit between these three models and ANFIS had the best goodness of fit among this three models. The influence of number of urban pixels in $3^{*} 3$ neighborhoods factor in urban development of Tehran Megacity is greater than the influence of other factors and on the other hand, slope had the lowest impact on urban development for this city in this period of time.

\section{Conclusion}

The purpose of using urban growth models for a given period of time is to know and regulate the location and intensity of land development. Obviously, it is more expensive to provide trunk urban infrastructure in an informal developed area to provide such services, or at least to protect the right-of-way needed for such services before building takes place. Thus, analyses and control how much a city will expand is seem to be necessary (Shlomo et al. 2005).

Monitoring urban expansion requires accurate and detailed datasets and appropriate methods for their analysis, modeling and interpretation. Nowadays, one of the most common question in the urban planning is how much acceptable degrees of development (location and amount) are reasonable.

Urban sprawl has so many merits and drawbacks. Low rate of crime and being safer urban area zone, clean air and also, low rate of costs are probably the most attracting factors of attracting population to this area. But, this phenomenon means car dependency growth. It has caused increasing daily trips, traffics and pollution, too. It also has increased infrastructure and transport costs.

GIS and remote sensing are capable to provide necessary information for planning proposals and can be assumed as a powerful and useful monitoring tool during the implementation of plans. Combination of remote sensing data, geospatial information systems tools and mathematical methods such as artificial intelligence algorithms as a powerful method can be developed for analyzing and modeling environmental phenomena such as urban expansion and has the potential to support such models by providing data and analytical tools for the study of urban planning.

Results of this study can be considered as a strategic guide for city planner, and help them for optimizing the future expansion allocation and enable them to balance 


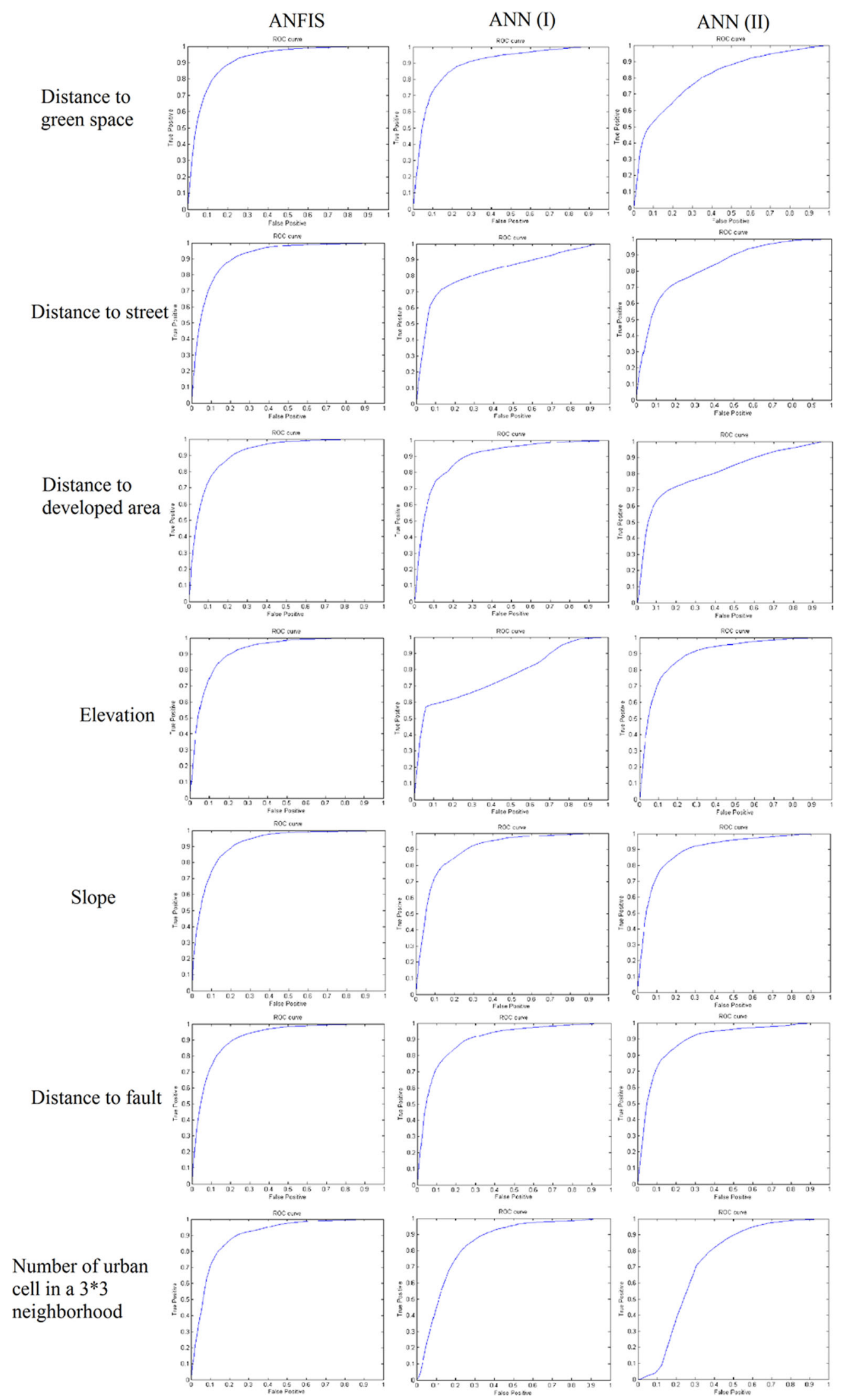

Fig. 13 The ROC obtained from deleting each variable 
urban expansion and ecological environment conservation and have a true perception about complex land use system.

\section{Compliance with ethical standards}

Conflict of interest The authors declare no conflict of interest.

\section{References}

Aghababaee H, Amini J, Tzeng YC (2013) Contextual PolSAR image classification using fractal dimension and support vector machines. Eur J Remote Sens 46:317-332

Alberti M, Weeks R, Booth D, Hill K, Coe S, Stromberg E (2002) Land cover change analysis for the Central Puget Sound Region 1991-1999. Final Report. Urban Ecology Research Laboratory, University of Washington, 2002. Download from: http://www. urbaneco.washington.edu/

Al-Kheder SAM, Wang J, Shan J (2008) Fuzzy inference guided cellular automata urban-growth modeling using multi-temporal satellite images. Int J Geogr Inf Sci 22(11-12):1271-1293

Almeida CM, Glerian JME, Castejon F, Soares-Filhob BS (2008) Using neural networks and cellular automata for modeling intraurban land-use dynamics. Int J Geogr Inf Sci 22(8-9):943-963

Anderson JR, Hardy EE, Roach JT, Witmer RE (1976) A land use and land cover classification system for use with remote sensor data. Geological Survey Professional Paper 964. US Geological Survey Circular, vol 671, pp 7-33

Batty M, Xie Y, Sun Z (1999) Modeling urban dynamics through GIS-based cellular automata. Comput Environ Urban Syst 23(3):205-233

Beguería S (2006) Validation and evaluation of predictive models in hazard assessment and risk management. Nat Hazards 37(3):315-329

Bhatta B (2009) Analysis of urban growth pattern using remote sensing and GIS: a case study of Kolkata, India. Int J Remote Sens 30(18):4733-4746

Ceccarelli T, Bajocco S, Luigi Perini L, Luca Salvati L (2014) Urbanization and land take of high quality agricultural soilsexploring long-term land use changes and land capability in Northern Italy. Int J Environ Res 8(1):181-192

Cheng J (2003) Modeling spatial \& temporal urban growth. Ph.D. Thesis, Faculty of Geographical Sciences, Utrecht University, Utrecht, The Netherlands

Dadras M, Shafri HZM, Ahmad N, Pradhan B, Safarpour S (2015) Spatio-temporal analysis of urban growth from remote sensing data in Bandar Abbas city, Iran. Egypt J Remote Sens Space Sci 18:35-52

Deep S, Saklani A (2014) Urban sprawl modeling using cellular automata. Egypt J Remote Sens Space Sci 17:179-187

Dubovyk O, Sliuzas R, Flacke J (2011) Spatio-temporal modelling of informal settlement development in Sancaktepe district, Istanbul, Turkey. ISPRS J Photogramm Remote Sens 66:235-246

Erfanifard Y, Khodaei Z, Fallah Shamsi R (2014) A robust approach to generate canopy cover maps using UltraCam-D derived ortho imagery classified by support vector machines in Zagros woodlands, West Iran. Eur J Remote Sens 47:773-792

Fanni Z (2006) Cities and urbanization in Iran after the Islamic revolution. Cities 23(6):407-411

Foroutan E, Delavar MR (2012) Urban growth modeling using fuzzy logic. ASPRS 2012 Annual Conference Sacramento, California, March 19-23, 2012

Goudie A (2006) The human impact on the natural environment: past, present and future. Blackwell Publishers, UK
Guan Q, Wang L (2005) An artificial-neural-network-based constrained CA model for simulating urban growth and its application. In: Auto-Curto Conference, 18-23, March 2005, Las Vegas, NV

Gupta MM, Rao DH (1994) On the principles of fuzzy neural networks. Fuzzy Sets Syst 61:1-18

Hana J, Hayashi Y, Cao X, Imura H (2009) Application of an integrated system dynamics and cellular automata model for urban growth assessment: a case study of Shanghai, China. Landsc Urban Plan 91:133-141

Hasse J (2007) Using remote sensing and GIS integration to identify spatial characteristics of sprawl at the building-unit level. In: Mesev V (ed) Integration of GIS and remote sensing. Wiley, New York, pp 117-143

Haykin SS (1999) Neural networks: a comprehensive foundation. Prentice-Hall, Upper Saddle River

Hosseinali F, Alesheikh AA, Nourian F (2013) Agent-based modeling of urban land-use development, case study: simulating future scenarios of Qazvin city. Cities 31:105-113

$\mathrm{Hu}$ Z, Lo C (2007) Modeling urban growth in Atlanta using logistic regression. Comput Environ Urban Syst 31(6):667-688

Huang C, Davis DS, Townshend JRG (2002) An assessment of support vector machines for land covers classification. Int $\mathbf{J}$ Remote Sens 23(4):725-749

Huang B, Zhang L, Wu B (2009) Spatiotemporal analysis of ruralurban land conversion. Int J Geogr Inf Sci 23(3):379-398

Jang JSR (1993) ANFIS: adaptive-network-based fuzzy inference system. IEEE Tran Syst Man Cybern 23(3):665-685

Jensen JR, Cowen DC (1999) Remote sensing of urban/suburban infrastructure and socio-economic attributes. Photogramm Eng Remote Sens 65:611-622

Jokar Arsanjani J, Helbich M, Noronha Vaz ED (2013) Spatiotemporal simulation of urban growth patterns using agent-based modeling: the case of Tehran. Cities 32:33-42

Jürgens C (ed) (2003) Remote sensing of urban areas. In: Proceedings of the ISPRS WG VII/4 symposium, Regensburg, 27-29 June 2003, vol XXXIV-7/W9. The international archives of the photogrammetry, remote sensing and satellite information sciences

Kavzoglu T, Mather PM (1999) Pruning artificial neural networks: an example using land cover classification of multi-sensor images. Int J Remote Sens 20:2787-2803

Kumar JM, Garg PK, Khare D (2008) Monitoring and modeling of urban sprawl using remote sensing and GIS techniques. Int $\mathbf{J}$ Appl Earth Obs Geoinf 10(1):26-43

Leao S, Bishop I, Evans D (2004) Simulating urban growth in a developing nation's region using a CA-based model. J Urban Plann Dev 130(3):145-158

Li X, Yeh A (2001) Calibration of cellular automata by using neutral networks for the simulation of complex urban systems. Environ Plann A 33(4):1445-1462

Li X, Yeh AG (2004) Analysing spatial restructuring of land use patterns in a fast growing region using remote sensing and GIS. Landsc Urban Plan 69:335-354

Liu Y (2009) Modelling urban development with geographical information systems and cellular automata. CRC Press. Taylor \& Francis Group, Boca Raton

Luck M, Wu JG (2002) A gradient analysis of urban landscape pattern: a case study from the Phoenix metropolitan region, Arizona, USA. Landsc Ecol 17(4):327-339

Maithani S (2010) Cellular automata based model of urban spatial growth. J Indian Soc Remote Sens 38(4):604-610

Masser I (2001) Managing our urban future: the role of remote sensing and geographic information systems. Habitat Int 25:503-512 
Meiyappan P, Dalton MB, O’Neill C, Jain AK (2014) Spatial modeling of agricultural land use change at global scale. Ecol Model 291:152-174

Melgani F, Bruzzone L (2004) Classification of hyperspectral remote sensing images with support vector machines. IEEE Trans Geosci Remote Sens 42(8):1778-1790

Mesev V (2003) Urban land use uncertainty: Bayesian approaches to urban image classification. In: Mesev V (ed) Remotely sensed cities. Taylor \& Francis, New York, pp 207-222

Miller RB, Small C (2003) Cities from space: potential applications of remote sensing in urban environmental research and policy. Environ Sci Policy 6:129-137

Moeller MS, Blaschke T (2006) Urban change extraction from high resolution satellite image. Paper presented at ISPRS Technical Commission II Symposium, 2006, Vienna, 12-14 July 2006

Mohammady S, Delavar MR (2015) Urban sprawl monitoring. Mod Appl Sci 9(8):1-12

Odindi JO, Mhangara P (2012) Green spaces trends in the city of Port Elizabeth from 1990 to 2000 using remote sensing. Int J Environ Res 6(3):653-662

Pahlavani P, Delavar MR (2014) Multi-criteria route planning based on a driver's preferences in multi-criteria route selection. Transp Res Part C 40:14-35

Pal M, Mathur PM (2005) Support vector machines for classification in remote sensing. Int J Remote Sens 26(5):1007-1011

Paola JD, Schowengerdt RA (1997) The effect of neural-network structure on a multispectral land-use land-cover classification. Photogramm Eng Remote Sens 63:535-544

Pham HM, Yamaguchi Y, Bui TQ (2011) A case study on the relation between city planning and urban growth using remote sensing and spatial metrics. Landsc Urban Plan 100:223-230

Pijanowski BC, Brown DG, Shellito BA, Manik GA (2002) Using neural networks and GIS to forecast land use changes: a land transformation model. Comput Environ Urban Syst 26(6):553-575

Pijanowski BC, Pithadia S, Shellito BA, Alexandridis K (2005) Calibrating a neural network-based urban change model for two metropolitan areas of Upper Midwest of the United States. Int J Geogr Inf Sci 19(2):197-215

Pijanowski BC, Tayyebi A, Delavar MR, Yazdanpanah MJ (2009) Urban expansion simulation using geographic information systems and artificial neural networks. Int $\mathrm{J}$ Environ Res 3(4):493-502

Pijanowski BC, Tayyebi A, Doucette J, Pekin BK, Braun D, Plourde J (2014) A big data urban growth simulation at a national scale: configuring the GIS and neural network based land transformation model to run in a high performance computing (HPC) environment. Environ Model Softw 51:250-268

Pontius RG, Schneider LC (2001) Land-cover change model validation by an ROC method for the Ipswich watershed, Massachusetts, USA. Agric Ecosyst Environ 85(1-3):239-248

Rafiee R, Mahiny AS, Khorasani N, Darvishsefat AA, Danekar A (2009) Simulating urban growth in Mashad City, Iran through the SLEUTH model (UGM). Cities 26(1):19-26
Rui Y (2013) Urban growth modeling based on land-use changes and road network expansion. Doctoral Thesis in Geodesy and Geoinformatics with Specialization in Geoinformatics, Royal Institute of Technology, Stockholm, Sweden

Sathish Kumar D, Arya DS, Vojinovic Z (2013) Modeling of urban growth dynamics and its impact on surface runoff characteristics. Comput Environ Urban Syst 41:124-135

Shlomo A, Sheppard SC, Civco DL (2005) The dynamics of global urban expansion. With Robert Buckley, Anna Chabaeva, Lucy Gitlin, Alison Kraley, Jason Parent, and Micah Perlin. Transport and Urban Development Department, World Bank: Washington

Statistical Centre of Iran. www.amar.org.ir

Sudhira HS, Ramachandra TV, Jagadish KS (2004) Urban sprawl: metrics, dynamics and modeling using GIS. Int J Appl Earth Obs Geoinf 5(1):29-39

Tayyebi A, Delavar MR, Pijanowski BC, Yazdanpanah MJ, Saeedi S, Tayyebi AH (2010) A spatial logistic regression model for simulating land use patterns, a case study of the Shiraz metropolitan area of Iran. In: Chuvieco E, Li J, Yang X (eds) Advances in earth observation of global change. Springer Press, New York

Tayyebi A, Pijanowski BC, Tayyebi AH (2011) An urban growth boundary model using neural networks, GIS and radial parameterization: an application to Tehran, Iran. Landsc Urban Plan 100:35-44

Tewolde MG, Cabral P (2011) Urban sprawl analysis and modeling in Asmara, Eritrea. Remote Sens 3:2148-2165

Thomlinson JR, Bolstad PV, Cohen WB (1999) Coordinating methodologies for scaling land cover classifications from sitespecific to global: steps toward validating global map products. Remote Sens Environ 70:16-28

Triantakonstantis D, Mountrakis G (2012) Urban growth prediction: a review of computational models and human perceptions. J Geogr Inf Syst 4:555-587

Tsoukalas LH, Uhrig RE (1997) Fuzzy and neural approaches in engineering. Wiley, New York

UNEP (2005) United Nations Environmental Program. Key facts about cities: issues for the urban millennium. United Nations Environmental Program, New York

Veldkamp A, Lambin EF (2001) Editorial: predicting land-use change. Agric Ecosyst Environ 85:1-6

Weng Y (2007) Spatiotemporal changes of landscape pattern in response to urbanization. Landsc Urban Plan 81:341-353

World Gazetteer (2012) http://www.world-gazetteer.com/

Wu J, Han J, Annambhotla S, Bryant S (2005) Artificial neural networks for forecasting watershed runoff and stream flows. J Hydrol Eng 10(3):216-222

Xie C, Huang B, Claramunt C, Chandramoul M (2009) Spatial logistic regression and GIS to model rural-urban land conversion. In: Proceedings of PROCESSUS Second International Colloquium on the behavioural, Toronto, 12-15 June 2009

Yeh AGO, Li X (2003) Simulation of development alternatives using neural networks, cellular automata and GIS for urban planning. Photogramm Eng Remote Sens 69(9):1043-1052 